\title{
A Practice of Anesthesia for Infants and Children, Sixth Edition
}

\author{
Charles J. Coté, Jerrold Lerman, Brian J. Anderson (Editors). Elsevier, 2019, Hardcover, \\ 1,256 pages. ISBN 978-0-323-42974-0
}

\author{
Maisie Tsang, BSc, MD
}

Received: 19 July 2018/ Accepted: 19 July 2018/Published online: 10 September 2018

(C) Canadian Anesthesiologists' Society 2018

Whether working in a highly specialized urban academic hospital setting or a rural community hospital, infants and children can come into our care at any time. This patient population has its own nuances and specifics. Although an anesthesia subspeciality, it goes without saying that children are not just "little adults". This textbook provides guidance and up-to-date information and research in the ever-evolving field of pediatric anesthesiology.

In this regard, A Practice of Anesthesia for Infants and Children, Sixth Edition, provides a useful resource for anesthesia departments worldwide regarding the most basic differences in physiology between children and adults. It also provides guidance for management of the most complex cases in pediatric anesthesia practice. It contains information useful for all levels of training and practice, and its earlier editions have served as mainstay textbooks for many pediatric anesthesia fellowships. The book is effectively organized and well referenced.

In this sixth edition, the authors have added some important, timely chapters, such as Pharmacogenomics, Perioperative Management of the Oncology Patient, and Massive Blood Transfusion. The pharmacogenomics chapter delves not only into the history of this research, but the recent relevance to our specialty, including opioid pharmacodynamics and the effects of other anesthetic agents and pain medications.

A helpful, laminated pocket reference guide comes with the textbook as well as access to an expanded online

M. Tsang, BSc, MD ( $\bowtie)$

Department of Anesthesia and Pain Medicine, Hospital for Sick Children, University of Toronto, Toronto, ON, Canada

e-mail: maisie.tsang@sickkids.ca version of the pocket reference from the Starship Children's Hospital in Auckland, New Zealand - all included in the purchase of this textbook. The pocket guide includes dosing (per kilogram) of resuscitation drugs and commonly and uncommonly used anesthetic medications, as well as an opioid conversion table. It also includes a highly useful table that summarizes transfusion "shortcuts", normal hemodynamic indices for age and weight, and handy tables for laryngeal mask airway, endotracheal tube, and laryngoscope sizing per age and weight. A Practice of Anesthesia for Infants and Children, Sixth Edition also includes accessibility to an expansive video library of specific techniques that may be used in the practice of anesthesia in the pediatric population.

It is useful to compare A Practice of Anesthesia for Infants and Children, Sixth Edition, with a similarly popular pediatric textbook, Smith's Anesthesia for Infants and Children, Ninth Edition, by Drs Peter Davis and Franklyn Cladis (which was also updated in 2017), as both books are considered by many as the "go to" sources for pediatric anesthesia, just as "Miller" and "Barash" are to the general discipline of anesthesia. A Practice of Anesthesia for Infants and Children, Sixth Edition, is organized by system (much like Barash's Clinical Anesthesia), whereas Smith's Anesthesia for Infants and Children, Ninth Edition is organized more traditionally in sections of Physiology, Pharmacology, and so on (much like Miller's Anesthesia). Both textbooks are also available in an eBook version, and they seem to be used interchangeably among pediatric anesthesia fellowships across North America.

The section on The Brain and Glands not only summarizes common and uncommon disorders and the best ways to provide anesthetics, it also delves into the 
ever-so controversial issue of the effects of anesthetics on neurodevelopment of the immature brain. It provides robust references to recent research, and it summarizes such research well (and within a few pages) - from proposed mechanisms to studying the specifics. The section on The Chest offers an excellent overview of the basics of the pediatric airway. It also dives into specific blockers one can use for one-lung ventilation in infants, along with photographs illustrating the differences between catheters.

Although both textbooks - the presently reviewed text and Smith's Anesthesia - provide in-depth looks into, and detailed references on, the specialty of pediatric anesthesia, I personally find A Practice of Anesthesia for Infants and Children, Sixth Edition an easier read. It gives the reader a detailed overview and addresses specific populations of patients, providing a "big picture" discussion on the management of patients representing those specific scenarios. In essence, this textbook provides a "one-stop shop" for the management of most situations an anesthesiologist may encounter within the specialty of pediatric anesthesia.

In summary, this textbook is versatile - residents could use it as a resource of the fundamentals of pediatric anesthesia, fellows could use it to delve into more of the specifics, and experienced attending anesthesiologists could use the book as a refresher and a reliable update of evidence-based medicine in our specialty. I recommend this textbook to any anesthesia resident, fellow, or staff member.

Conflicts of interest None declared.

Editorial responsibility This submission was handled by Dr. Hilary P. Grocott, Editor-in-Chief, Canadian Journal of Anesthesia. 